\title{
TER HERINNERING AAN PROF. DR GEROLD STAHEL
}

\author{
EN ZIJN WERK VOOR DE LANDBOUW EN HET \\ NATUURONDERZOEK IN SURINAME
}

DOOR

\section{A. Reyne}

Gerold Stahel is op 29 Juni 1887 te Gossau (kanton Zürich) in Zwitserland geboren, en in 1911 te Bazel gepromoveerd ${ }^{\mathbf{1}}$ ). Van Mei 1914 tot September 1948 (behoudens een korte onderbreking in 1921) is hij werkzaam geweest aan het Landbouwproefstation in Suriname, aanvankelijk als plantkundige, sedert Januari 1919 als directeur. In September 1948 kreeg hij als zodanig eervol ontslag ,,onder dankzegging voor de gedurende zeer langen tijd aan den lande bewezen gewichtige diensten". Stahel bleef nog tot October 1950 in Suriname om zijn werk ten bate van de cacaocultuur voort te zetten. Daarna is hij met zijn vrouw teruggekeerd naar Zwitserland, waar zij zich te Quinten aan de Walensee vestigden. In de jaren 1918-1924, toen ik aan bovengenoemd proefstation verbonden was, heeft Stahel mij reeds foto's van de Walensee getoond, waar hij na zijn pensionnering zou gaan wonen. Toen het in November 1950 eindelijk zover was gekomen, heeft hij helaas slechts kort van zijn rust mogen genieten. Reeds in Januari 1953 is hij ziek geworden, en verhuisde hij naar Bern om zich daar te laten behandelen. Te Bern werd hij in het ziekenhuis opgenomen wegens een leverkwaal, vermoedelijk het gevolg van oude malaria. Later werd hij door zijn vrouw thuis verpleegd, waar hij 13 Januari 1955 is overleden.

Stahel heeft zeer veel bijgedragen tot het natuurwetenschappelijk en landbouwkundig onderzoek in Suriname. Hij was een buitengewoon begaafd .en veelzijdig onderzoeker, met een zeldzame energie en werkkracht. Nu deze rusteloze werker is heen-

1) Zijn dissertatie handelt over ,Stickstoffbindung durch Pilze bei gleichzeitiger Ernährung mit gebundenem Stickstoff" en is verschenen in Jahrb. f. wiss. Botanik, Bd, 49, 1911. Zijn promotor was Prof. Dr Alfr. Fischer. De hierbij afgebeelde foto van Prof. Stahel werd in 1944 opgenomen achter zijn huis in de Cultuurtuin te Paramaribo.

West-Indische Gids XXXVI

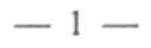


gegaan, is het zeker gepast om een overzicht te geven van het vele en belangrijke werk, dat hij in en voor Suriname gedaan heeft.

Toen Stahel in Mei 1914 in Suriname aankwam, werd hij al dadelijk voor een belangrijk probleem geplaatst, nl. dat van de oorzaak der krullotenziekte, waardoor de cacaoproductie in Suriname van 1895-1905 met $60 \%$ was gedaald. In 1901, toen de toestand kritiek werd, zond de Nederlandse Regering Prof. Dr F. A. F. C. Went, die vroeger directeur-plantkundige van een proefstation op Java was geweest, naar Suriname. Went heeft na zijn reis vier rapporten gepubliceerd over de landbouw in Suriname en op de Nederlandse Antillen. In het eerste rapport werd o.a de stichting van een proefstation te Paramaribo aanbevolen, waaraan in 1903 gevolg werd gegeven. Het vierde rapport handelde over ,De ziekteverschijnselen van de cacaoplant”. Went was de eerste, die levende krulloten ter plaatse bestudeerde. Hij vond tussen de cellen een schimmel, die in reincultuur echter niet wilde fructificeren. Infectie met het mycelium der reincultures had geen resultaat. Went hield deze schimmel voor de oorzaak der ziekte, maar stelde tevens vast, dat het bewijs daarvoor nog door infectieproeven geleverd moest worden.

Dr C. J. J. van Hall, de eerste Directeur van Landbouw in Suriname, en de landbouwassistent Drost, onderzochten de krullotenziekte uitvoerig, en legden de resultaten vast in Bulletin 16 van genoemd Departement. De geïsoleerde schimmel fructificeerde in hun reincultures wèl, en werd beschreven als Colletotrichum luxificum $\mathrm{n}$. sp. maar het bewijs door middel van infectieproeven, dat deze schimmel inderdaad de oorzaak der krullotenziekte was, werd niet geleverd. Wel werd vastgesteld, dat soortgelijke vruchtlichamen op afstervende krulloten en versteende cacaovruchten voorkomen. In 1913 publiceerde J. B. Rorer een artikel, waarin vastgesteld werd, dat genoemde Colletotrichum in Trinidad een gewone saprophyt is op plantenresten, vooral op vruchten, hoewel de krullotenziekte daar niet voorkwam. Rorer reisde naar Suriname om de zaak nader te bestuderen, maar vond bij het Landbouwdepartement geen gehoor (Drvan Hall was inmiddels vertrokken naar Oost-Indië), zodat hij zijn onderzoek op de plantage St Barbara verrichtte, daartoe uitgenodigd door de eigenaar. Rorer isoleerde steeds dezelfde schimmel uit krulloten, en hield deze voor de oorzaak der ziekte, maar het gelukte hem niet om de schimmel tot fructificatie te brengen. Infecties met het mycelium hadden geen resultaat. 
Daar dit mycelium steeds zg. ,clamp connections" vertoonde, besloot hij, dat het een Basidiomyceet moest zijn.

Nadat Stahel in Mei 1914 zijn dienst bij het Landbouwproefstation aanvaard had, heeft hij onmiddellijk zijn aandacht op dit probleem gevestigd. Op dode krulloten werden een drietal paddestoeltjes gevonden, o.a. een Marasmius-soort. Deze Marasmius, later door Stahel beschreven als $M$. perniciosus, werd het eerst in studie genomen. Met de sporen daarvan konden krulloten kunstmatig verwekt worden, ook in het geïsoleerde Bosnegerdorp Gansee, dat steeds vrij van de ziekte was gebleven. De resultaten werden in 1915 gepubliceerd in Bull. $3^{1}$ ). In 1919 werden verdere onderzoekingen over de biologie der krullotenziekte en haar bestrijding bekend gemaakt in Bull. 39. De bestrijding bestond in het geregeld wegsnijden der krulloten door een vaste ploeg arbeiders. Aanvankelijk werden de krulloten uit de velden gedragen en verbrand. Later bleek, dat dit niet nodig was, en zeker niet lonend.

In 1923 onderzocht Stahel krulloten uit Ecuador, in 1928 uit Trinidad, en in 1935 uit Brazilië, toen de ziekte ook in deze landen in de cacaoplantages was binnengedrongen. Men verzocht hem naar Ecuador en Trinidad te komen voor een nader onderzoek; alleen aan het laatste verzoek heeft hij gevolg gegeven.

In 1917 had Stahel zijn belangrijke studie over de Zuidamerikaanse Hevea-bladziekte voltooid, en gepubliceerd in Bull. 34. Hevea brasiliensis werd in 1896 in Suriname ingevoerd. Begin 1912 waren er ca. 250.000 bomen van 1-4 jaar aanwezig, als tussenplanting in bacovenvelden, waarin vaak ook koffie en cacao stond. De wilde Hevea guianensis, die in de bossen van Suriname vrij algemeen voorkomt, wordt vaak aangetast door een schimmel, Melanopsammopsis Ulei, die P. Hennigs reeds in 1904 van wilde Hevea aan de Boven-Amazone als Dothidella Ulei beschreven heeft. Bij wilde Hevea veroorzaakt deze bladziekte slechts weinig schade, maar in gesloten aanplant werkt de ziekte ruĩneus, zoals later gebleken is. Toen de Hevea-cultuur in Suriname reeds was afgeschreven, was de Hevea-plantage van de „Compagnie des Mines d'Or" aan de Lawa (Boven-Marowijne) nog gezond. In het vogrjaar van 1918 begon de bladziekte ook daar ruĩneus op te treden; dit was blijkbaar een gevolg van infectie door wilde Hevea in de aangrenzende bossen. Binnen een half jaar stierf $1 / 3$ der ca. 40.000 Hevea-bomen, waarna de plantage werd

1) Bull. en Meded. heeft in dit artikel steeds betrekking op de bulletins en mededelingen van het Departement van Landbouw (resp. Landbouwproefstation) in Suriname. 
afgeschreven. Na deze laatste Hevea-ramp schreef Stahel in het landbouwtijdschrift West Indië (Jrg. IV, 1919, blz. 64) : ,De Zuidamerikaanse Hevea-bladziekte maakt de pararubber-cultuur in Zuid Amerika onmogelijk". Dat deze conclusie juist was, is later duidelijk gebleken bij de grote Hevea-plantages, die Ford in het Amazone-gebied liet aanleggen om rubber te leveren voor zijn autofabrieken. Alleen in Oost-Azië, ver van het vaderland der Hevea, is de Hevea-cultuur tot bloei gekomen.

In 1920 verscheen Stahel's eerste studie over de zeefvatenziekte (phloeem-necrose) der Liberia-koffie in Suriname (Bull. 40). Deze ziekte was reeds lang in Suriname bekend, maar haar oorzaak niet opgehelderd. In 1917 ontdekte Stahel, dat de zeefvaten der zieke bomen gestorven waren, plat gedrukt en met gom gevuld. In 1930 heeft hij (samen met Bünzli) het onderzoek over deze ziekte voortgezet. Toen bleek hem, dat de vergomde zeefvaten eerst in het eindstadium der ziekte voorkomen, en dat in een vroeger stadium de jonge, nog levende zeefvaten door herhaalde deling in 3-8 kleinere gesplitst worden. Bij verder onderzoek vond Stahel ten slotte, dat de zieke zeefvaten aanvankelijk gevuld zijn met Flagellaten, die hij als Phytomonas leptovasorum beschreef (Phytopathol. Zeitschr. IV, p. 65-82, 539-544, VI, p. 335-357; 1931-1933). In Stahel's laatste publicatie over de zeefvatenziekte (Netherl. Journ. of Agric. Science, vol. 2, 1954, p. 260-264), die een samenvatting geeft van zijn vroegere publicaties over dit onderwerp, wordt de betrokken Flagellaat Leptomonas davidi genoemd. Door schrijver dezes werden in 1924 een drietal schildluizen gevonden, die in het phloeem der koffiewortels zuigen. Vermoed werd, dat deze wortelluizen, die soms zeer talrijk voorkomen, de ziekte overbrengen. Infectieproeven met Rhizoecus coffeae Laing, de meest algemene soort, gelukten echter niet, hoewel Stahel in het lichaam talrijke Flagellaten vond. Later heeft Stahel de wants Lincus spathuliger Breddin (fam. Pentatomidae) voor de overdrager der zeefvatenziekte gehouden (Meded. 7 van Jan. 1934; J. G. Leach „,Insect transmission of plant diseases", 1940, pp. 392-394). Voor zover mij bekend is, heeft hij het definitieve bewijs daarvoor niet kunnen leveren, en zijn de infectieproeven evenals die met de wortelluizen negatief uitgevallen. Stahel schreef mij eens (3.V.1951), dat de zeefvatenziekte het moeilijkste onderzoek was, dat hij ooit verricht had. Hij verwachtte, dat zijn opvolgers de resultaten van zijn onderzoek zouden bevestigen en de wijze van overdracht door genoemde wants nader uitwerken. 
Stahel's onderzoek over de Sclerotiumziekte der Liberia-koffie in Suriname verscheen in 1921 (Bull. 42). In 1937 publiceerde hij uitvoerige onderzoekingen over twee bladziekten van de banaan (Bull. 53; Tropical Agriculture XIV). Verder verschenen van zijn hand artikelen over de krulloten van Eugenia latifolia Aublet (1933), over een bladvlekkenziekte van Citrus (1940), en over de schimmeltuinen der bladsnijdermieren (Atta cephalotus en $A$. sexdens L.) in 1938, 1941 en 1943.

Ook aan schadelijke insecten wijdde Stahel zo nu en dan zijn aandacht. In 1917 verscheen een korte mededeling over een schorskevertje (Xyleborus perforans) in Liberia-koffie, in 1925 volgden twee mededelingen over een Stephanoderes sp., die eerst voor de beruchte koffiebessenboeboek ( $S$. hampei Ferr.) werd aangezien, maar later een onschuldige soort bleek te zijn, waarop de biologie reeds wees. Verder publiceerde hij in de jaren 19391941 , in samenwerking met D. C. Geijskes, uitvoerige onderzoekingen over de reeds genoemde bladsnijdermieren (nestbouw, schimmeltuinen, bestrijding). In 1938 had hij reeds een uitvoerig verslag uitgebracht over de schimmeltuinen van Atta cephalotes aan het Botanisch Congres te Rio de Janeiro (Anais Primeira Reunião Sul-Americana de Botanica, I, p. 199-213).

Naast zijn onderzoekingen over plantenziekten heeft Stahel ook ander belangrijk werk verricht voor de Surinaamse landbouw, in het bijzonder voor de selectie van cacao. Hij hield daarover reeds op 28 Juni 1916 voor de Surinaamse Landbouwvereeniging een lezing, welke leidde tot de oprichting van het Surinaamsche Selectiefonds op 2 Augustus d.a.v. In 1919 verscheen zijn eerste verslag over het voor de selectie van koffie en cacao verrichte werk (Bull. 36), en in 1925 zijn handleiding voor het oculeren van cacao (Bull. 49). Helaas is de cacao-cultuur in Suriname vrijwel te gronde gegaan na de felle droogte van 1925-1926. Er scheen een noodlot op de grote cultures in Suriname te rusten, dat na de bacoven en de Hevea ook de cacao trof. De bevolkingscultuur van cacao aan de Goudkust in Afrika had zo langzamerhand op de wereldmarkt een overheersende positie ingenomen, waartegen de plantagecacao moeilijk kon concurreren. Toen de cultuur aan de Goudkust door ziekte sterk achteruit begon te gaan, en er na de oorlog van 1939-'45 een wereldtekort aan cacao ontstond, is men in de andere cacao-landen weer belang gaan stellen in de cacao als plantagecultuur, omdat de prijs door het tekort zeer sterk was gestegen. Op 1 Mei 1947 hield Stahel een lezing over de herleving der cacao-cultuur. In hetzelfde jaar 
heeft hij in Meded. 10 en 11 een uitvoerig résumé gegeven over de positie dezer cultuur. In Juni 1948 verscheen zijn publicatie over de bladstekken-methode voor het vermenigvuldigen van cacao (Bull. 61), een door hem gevonden methode om zo snel mogelijk het uit Trinidad ontvangen superieure cacao-materiaal (5 hoog producerende clonen) te vermeerderen. Toen hij in September 1948, na 34 jaar aan het proefstation in Suriname gewerkt te hebben, met pensioen ging, bleef hij nog tot October 1950 werkzaam voor deze cacao-kwekerij.

Ook voor de sinaasappel- en de rijstcultuur heeft Stahel veel werk verricht; kleinere onderzoekingen hadden betrekking op koffiebereiding, oliepalm, perubalsem, vlechtstroo (Carludovica), soya enz. Verder publiceerde hij in 1942 een belangrijk werk over de nuttige planten van Suriname (Bull.57), waarvan in 1944 een tweede vermeerderde druk verscheen. Ook schreef hij in 1944 een brochure over ,,Surinam timbers” (2de druk 1947). De jaarverslagen 1914-1950 van het Departement van Landbouw (resp. Landbouwproefstation) in Suriname geven een uitvoerig overzicht over het vele werk, dat Stahel voor de Surinaamse landbouw heeft verricht. Als directeur van het Landbouwproefstation was hij ook belast met de Meteorologische Dienst in Suriname, waaraan hij veel aandacht besteedde.

Stahel heeft verder belangrijk werk gedaan voor het onderzoek der flora van Suriname. Tezamen met de houtvester J. W. Gonggrijp heeft hij zeer veel herbarium-materiaal verzameld, dat aan het Botanisch Museum te Utrecht bewerkt is, of bewerkt wordt (vergl. de grote „Flora of Surinam” van Prof. Dr A. A. Pulle en medewerkers, die sedert 1931 verschijnt). Stahel heeft ook belangrijk bijgedragen tot de kennis der Surinaamse flora door zijn eigen publicaties. Behalve de reeds genoemde werken over plantenziekten, de nuttige planten en de houtsoorten van Suriname, publiceerde hij in 1918 een uitvoerige verhandeling over de bloeiwijze, en in 1928 over de bloembiologie van cacao; verder enige kleinere botanische artikels.

Stahel voelde zich zeer aangetrokken tot de binnenlanden van Suriname, en vertoefde daar vaak. Met J. W. Gonggrijp ondernam hij een tocht naar de Hendriktop (zie W.I. Gids 1923), en in 1926 was hij leider van de Expeditie naar het Wilhelminagebergte (vergl. Bulletin 82-87 van de Maatschappij ter bevordering van het natuurkundig onderzoek der Nederlandsche koloniën). In 1920 reisde hij met schrijver naar een wild cacao-bos in het Coppename-gebied, waarbij bleek, dat deze wilde cacao 
de bakermat van de krullotenziekte der cacaoplantages was (Ind. Mercuur 1920). In 1923, toen er sprake was van hervatting der bacoven-cultuur, ging Stahel in opdracht van de Gouverneur naar Centraal-Amerika, waarbij hij ook Brits Guyana, Trinidad, Venezuela en Curaçao bezocht. Behalve aan bananen, wijdde hij op deze reis ook zijn aandacht aan Citrus, cacao, en andere onderwerpen (zie Bull. 45). Bij alle grotere reizen van natuuronderzoekers in het binnenland was Stahel steeds van de partij. Hij heeft ook een artikel geschreven over de bovenlandse Indianen (1942) en over het Bosneger-vraagstuk (1944); verder tezamen met Geijskes gepubliceerd over verkenningsvluchten boven Suriname's binnenlanden (1940), en met H. J. Müller over de vruchtbaarheid van de grond in die binnenlanden (1933; Bull. 52).

In het Koninklijk Instituut voor de Tropen te Amsterdam bevinden zich vele foto's van het Surinaamse binnenland, die door Stahel opgenomen zijn, verder veel ander materiaal, dat van hem afkomstig is. Hij is één van de grootste bevorderaars van het natuurwetenschappelijk onderzoek van Suriname geweest. Destijds heeft hij ook gedacht aan een gasten-laboratorium in Suriname voor buitenlandse onderzoekers, zoals er een te Buitenzorg was gesticht (vergl. W.I. Gids 1920).

Schrijver dezes heeft het voorrecht gehad met Stahel aan het proefstation te Paramaribo te werken in de jaren, waarin hij zijn belangrijke onderzoekingen over de krullotenziekte der cacao, de Hevea-bladziekte, en de zeefvatenziekte der Liberia-koffie verrichtte. Stahel was een zeer nauwgezet onderzoeker. Geen moeite was hem te veel, wanneer deze voor zijn werk nodig was. Zo nam hij eens 48 uur achtereen elk uur de sporenproductie van de krulloten-paddestoel op, en verscheen hij op het proefstation met een wekker, die elk uur ratelde. Voor zijn onderzoek over de Hevea-bladziekte had hij gegevens nodig over de dauwvorming op de bladen, waarvoor hij enige nachten doorbracht in de kruinen van Hevea-bomen in de Cultuurtuin. Zijn ijver, enthousiasme, en ook zijn optimisme, scheen geen grenzen te kennen. Wanneer hij een bepaald doel voor ogen had, was hij moeilijk daarvan af te brengen. Toen de planters er op wezen, dat het geen zin meer had om het onderzoek over de Hevea-bladziekte voort te zetten, omdat de Hevea-cultuur in Suriname reeds was afgeschreven, zette hij door, en antwoordde: ,, anders komt niets daaruit”. Er kwam ook iets uit, zoals de uitstekende verhandeling van Bull. 34 aantoont. Het is begrijpelijk, dat Stahel's onverzettelijk karakter, waardoor hij bij zijn onderzoek zo veel bereikte, meermalen 
aanleiding gaf tot onenigheid met anderen, hoewel hij overigens een goedhartige natuur bezat. „Chacun a les défauts de ses vertus". Dit gold ook voor hem, maar zijn fouten werden zeer ver in de schaduw gesteld door zijn deugden.

Stahel's werk heeft buiten Suriname al spoedig de aandacht getrokken. Toen hem een betrekking in Oost-Indië werd aangeboden met een belangrijk hoger salaris, pasten de Surinaamse planters het tekort bij. In Maart 1921 werd Stahel benoemd tot hoogleraar in de phytopathologie en mycologie aan de Landbouwhogeschool te Wageningen. Op 1 Juli 1921 hield hij zijn inaugurale rede over: „De infectieproef in de phytopathologie”, maar op de laatste dag van dat jaar was hij al weer teruggekeerd in Suriname. Hij had in Wageningen alleen een collegezaal en een geheel leeg laboratorium tot zijn beschikking en diende onmiddellijk een begroting in voor drie kassen à f 20.000 , maar dit voorstel werd afgewezen, omdat het viel in een periode van bezuiniging. Stahel was niet bereid om onder deze omstandigheden te beginnen, en hij vroeg ontslag aan zonder ooit een college gegeven te hebben. Toen hij voor zijn vertrek bij de Minister kwam, en nog eens zijn bezwaren te berde bracht, zei deze tegen hem: ,,maar U had toch kunnen beginnen met college te geven", waarop Stahel (wiens Nederlands toen nog niet volmaakt was) had geantwoord: „,Maar, Excellenz, er is daar geen glasje in dat hele labor". Stahel was niet politiek aangelegd, hij hield niet van schipperen of halve maatregelen, en dus keerde hij dadelijk naar Suriname terug.

In 1924 werd Stahel benoemd tot correspondent van de Koninklijke Nederlandse Akademie van Wetenschappen, en in 1926 (na zijn expeditie naar het Wilhelmina-gebergte) tot ridder in de Nederlandse Leeuw. Voor zover ik weet, zijn hem na het professoraat te Wageningen geen andere betrekkingen meer aangeboden gedurende de 29 jaren, die hij nog in Suriname doorbracht. Ik heb wel eens de indruk gekregen, dat zijn werk daar later niet meer voldoende gewaardeerd werd. Stahel schreef mij eens, dat het onder Gouverneur Rutgers prettig dienen was. Deze Gouverneur, die zijn loopbaan zelf als phytopatholoog begon, later directeur van het proefstation der A.V.R.O.S. te Medan was, en Directeur van Landbouw te Buitenzorg, heeft zeker Stahel's verdiensten beter kunnen beoordelen dan één van zijn voorgangers.

Onder de proefstation-werkers in Oost- en West-Indië was Stahel een van de meest uitblinkende onderzoekers; zijn veelzijdige arbeid, vastgelegd in tal van uitstekende publicaties, zal nog lang nawerken, en niet spoedig vergeten worden. 